International Journal of

Health, Medicine and

Nursing Practice

(IJHMNP)






\title{
Knowledge, Attitude, Practices and Obstacles to Provide Urinary Incontinence Care among Nurses
}

\author{
${ }^{*}$ Akmal Shehzad \\ Post RN BScN student (The University of Lahore) \\ *Corresponding Author's Email: akmalaslam133@gmail.com \\ ${ }^{2}$ Kausar Parveen \\ Assistant professor at LSN (The University of Lahore) \\ ${ }^{3}$ Muhammad Afzal \\ Associate Professor at LSN (The University of Lahore)
}

\begin{abstract}
Purpose: Nurses are personalities who stand with patients at all times to listen and solve their problems. Excellent knowledge, good practices and positive attitude of nurses proves very effective for improving patients with urinary incontinence in a mannered way. The study objective was, (a) evaluate the knowledge, attitudes and practices among nurses of urinary incontinence, (b) reveal the relationship between knowledge, attitudes and demographic characteristics and (c) evaluate obstacles faced by nurses during urinary incontinence care.

Methodology: A cross-sectional study was accompanied in a government tertiary care hospital in Lahore, Pakistan. To analysis the variables statistical packages for social sciences version 25 was used. Pearson correlation test was used to correlate the knowledge, attitude and practices regarding urinary incontinence. Less than $\mathrm{P}>0.05$ is significant.

Findings: 164 nurses contributed in the studies and 157 completed and return the survey questioner, with return rate of $95.7 \%$. Of those, $117(74.5 \%)$ were female nurses and $40(25.5 \%)$ were male nurses. There is a significant correlation found between knowledge with attitude items 0.046 and knowledge with practice items 0.039 . The study respondents have good knowledge, positive attitude but wrong practices regarding urinary incontinence.

Unique contribution to theory, practice and policy: It is concluded that Nurses have good knowledge, positive attitude but wrong practices that require special training or workshops to managing and treating incontinence more efficiently. This helps to bring significant improvement in urinary incontinence care and helps to lower the heath care cost. Such clinical guidelines need to be made within the organizations to manage a significant proportion of patients with urinary incontinence.
\end{abstract}

Keywords: Knowledge, Attitude, Practices, Obstacles, Urinary incontinence, Nurses 


\section{INTRODUCTION}

Urinary incontinence is a condition, when volunteer bladder control is lost. This could occur even though a person is sneezing or coughing. Leakage of urine without control can be annoying and any person can experience it at any age group. It effect on both men and women. This condition is generally Studies shows that this is a common issue with women and it can cause emotional restrain among physical and social activities resulting in compromised quality of life. UI cannot put the on risk but strongly impact on patients' life style in sense of social interactions and physical comfort. For treating and curing urinary incontinence the yearly health care expenses have been projected to be more than 65 billion dollars (Hu \& Pierre, 2019).

The occurrence of urinary incontinence during the period of pregnancy in Europe is 26 to $71 \%$, south and north America is 43 to $63 \%$ and in Pakistan 45\%. There are many types of UI are found all around the world but the most common types are mix and stress incontinence. The women with late weeks of pregnancy face UI with low standard of living. During the period of pregnancy UI needs prompt evaluation by physician to provide quality care. Statics revealed that about 50\% of women experience UI during their life span (Yaqub, Habib, \& Shaheen, 2019). Nurses play a vital role in detecting, evaluating, monitoring, and preventing patients from facing urinary incontinence (Caliskan, Gulnar, Aydogan, Bayram, \& Yagci, 2019). A descriptive study accompanied amongst 756 health care providers showed that health care providers' knowledge, attitudes, and practices are highly important to improve patients' quality of life. Nurses play more effective role than other healthcare professionals in providing education, exercises and treatment of urinary incontinence (Jang et al., 2015). However, many cross-sectional studies have shown that many nurses have very low knowledge of prevention, treatment and management of UI (Keilman \& Dunn, 2010).

An optimistic attitude is necessary to put knowledge into practice as knowledge without help of attitude is not adequate for positive behavior. Practice short fall is a gap between knowledge and practice which suppress positive attitudes towards UI (Kelly \& Byrne, 2006). Although UI is very common but only few women seek regardless of many effective treatments. Physicians should identify and treat the issues along with UI. If they are unable to treat the underlying cause then they must refer the patient to a specialist (Lukacz, Santiago-Lastra, Albo, \& Brubaker, 2017). Complications related to chronic urinary incontinence include: skin problems such as sores on wet skin, rashes or skin infections, urinary tract infection (UTI) and impact on personal life can happen. Urinary incontinence is not constantly preventable. However, UI can be reduced by healthy balance weight, pelvic floor exercises, avoid use of caffeine or alcohol, quit smoking (Abrams et al., 2018).

Categories of UI consists of, stress urinary incontinence is leakage of urine with compression on bladder by lifting heavy objects or even a person laughs, sneeze and cough. Urge urinary incontinence is a condition in which involuntary urine lost by a strong urge, caused by diabetes, infection or acute brain disorder. Overflow urinary incontinence a continuous dribbling of urine, caused by bladder that doesn't empty totally. Functional urinary incontinence is state of mental or physical impairment that keeps a person to making it to the toilet. Mixed urinary incontinence is experienced by a people who have more than one type of urinary incontinence. UI assessment depends on clinical signs and symptoms and is different in children, men, women and older adults. On initial assessment diagnostic test are performed to rule out the underline cause like infection. Most of the time conservative treatment is used which includes physiotherapy and lifestyle changes. If diagnosis is not clear or primary therapies are failed to 
overcome the issue then invasive interventions or surgery methods are being used (Thüroff et al., 2011).

\section{LITERATURE VIEW}

The analyses of the literature make known that there are negative responses by nurses toward urinary incontinence. Knowledge among nurses related to urinary incontinence is a central blockade in the application of actual incontinence treatments. As a result, it is important to assess nursing staff knowledge, attitude and practice in urinary incontinence care so that nurses can obtain satisfactory training and education to overcome the obstacles in providing care for patients with urinary incontinence. A study was conducted by Jokhio, Rizvi, \& MacArthur in 2013 in a community in a village Sindh, a province of Pakistan and study shown that the occurrence of urinary incontinence compared to other developing countries of the world in rural areas of Pakistan registration of urine problem has been found very low, but this problem is usually found in women and affects their daily lives very much. There are very few people who get medical facilities to get out of urinary problem. A descriptive study was done in 2017 in a Military Hospital Rawalpindi to approach the incidence of UI and its related risk factors during pregnancy. Women quality of life during pregnancy can be improved with the help of communicating knowledge about preventive strategies during pre-birth period (Yaqub, Habib, $\&$ Shaheen, 2019). Urinary incontinence is predominant during the period of pregnancy. There was association in reduced risk of UI throughout pregnancy with previous use of contraceptive hormones (Kok, Seven, Guvenc, \& Akyuz, 2016).

For the very first-time international consultation on incontinence was developed in 1988 . According to that flow process, an algorithm was presented for the management of incontinence in a detailed structure (Abrams et al., 2018). Incontinence related screening questionnaires, at least three-day voiding record, measure the post-void residual and cough stress test are helpful tools during initial assessment. For all patients urinalysis should be wellarranged. In a series of distinct stages, methods to treat are directed at the subtype of urinary incontinence, which start with conservative management, mounting to physical devices and then medications, followed by referral to surgical interventions. Lifestyle changing, pelvic floor (strengthen) exercises, proper fluid intake, weight loss and cessation of smoking are proposal as to the best course of action for all types of urinary incontinence. FDA (Food and Drug Administration) from America (USA) have still not permitted stress incontinence treatment with medication. Pharmacologic therapy includes antimuscarinic and mirabegron medications are recommended for urge incontinence (Hu \& Pierre, 2019).

Urinary incontinence is a medical problem with major influence equally on the lives of people experiencing incontinence and their caregivers as well. It causes significance inferences for local health economies in terms of delivery of health and social care to individual client or a whole community. Study reveals that Optimum Continence Service Specification (OCSS) helps in a decrease of urinary incontinence, better-quality of life, and also lesser healthcare costs (Franken, Corro Ramos, Los, \& Al, 2018). Women of every age are victim of urinary incontinence. Past history, physical examination related to incontinence and UI stress diagnostic test can guide physician to diagnose urinary incontinence. Initial managing steps consist of alteration in behavior and lifestyle changes. Treatment of urgency incontinence can be done with drug therapy but in conservative measures it is not helpful. Furthermore posterior tibial nerve stimulation and sacral neuromodulation are used for drug refractory urgency 
incontinence. For stress urinary incontinence midurethral synthetic slings are Safe surgical option (Wood \& Anger, 2014).

Urinary incontinence effects on the quality of life on both gender and is parallel in frequency by age. Family physicians evaluate the rout cause and there is no need for further evaluation by urologist or gynecologist. The rudimentary workup is targeted at recognizing possible revocable causes and it is considered as chronic if there no reversible cause is acknowledged and needs to be jump on the next step. The subsequent phase is to detect the type of urinary incontinence which includes overflow, stress, and urge, functional and mixed. If it comes to know what kind of disease is, it is easy to treat it, if the type of urinary incontinence is not clear including laboratory test, then appointment to urologist or gynecologist should be considered (Khandelwal \& Kistler, 2013).

\section{METHODOLOGY}

A descriptive study was accompanied during February, 2021 to April, 2021 in a government tertiary care hospital in Lahore. The study sample included 164 nurses who participated in study but only 157 nurses return the form after completion. Nurses who participated in study were working in radiation department, urology wards, dialysis wards, ICU (medical and surgical), coronary care units, neurosurgery department, gynecology wards and outpatient clinics. Participants were explained about the study plan and purpose. Inclusion criteria for the participants was, participants must be nurses and agree to participate in the studies. Nurses who were not willing to participate and those who will not complete the forms, student nurses and other healthcare professionals were excluded from the study.

After taking informed consent, participants were requested to fill-up a questioner including 5 tables covering demographic data (characteristics), urinary incontinence practices form, urinary incontinence knowledge questioner, urinary incontinence attitude scale that comprised likert-type questions and obstacles faced by nurses while providing urinary incontinence care to patients in different settings. These tables were established by the researchers based on the existing literature and studies. The characteristics data table kept in check about nurses' gender, education status, workplace, and duration of service providing, special education on urinary incontinence, any tool used by nurses to evaluate UI and provide nursing interventions. Practice form included whether they inquire about the number of continent voids, inquire as to alterations in bowel habit and ask about use of pads or any other protective devices. The answer always scored as 03 , usually as 02 , sometimes as 01 , never as 0 score were marked. Maximum score for practice form was 09 and minimum was 0 (Henderson \& Kashka, 2000). The obstacles faced by nurses in provision of urinary incontinence care were, no patient follow-up may be due to lack of education or lack of interest, patients are not stick to treatment and care plans at home, patient education material is not available and there is no proper space in hospital to evaluate patient with urinary in continence, no record keeping method, patient feel hesitate to share their sensitive issues and one of the most common and important issue was lack of knowledge and training for nursing staff. The urinary incontinence knowledge table was established by the researchers' existing literature (Caliskan, Gulnar, Aydogan, Bayram, \& Yagci, 2019). Those questions measured nurses' knowledge regarding urinary incontinence and its types, drugs and diseases that lead to UI, different type of UI, intervention for UI, impact of UI on person's life and his or her personal and social relationships. The questions contained true and false statements to which contestants answered true, false, and I don't know (which was scored as false). Correct replies were given 1 point and incorrect replies were given as 0 
points. The urinary incontinence attitude scale table was developed by the researchers' existing literature (Yuan, Williams, Liu, \& Nursing, 2011). Statements on the urinary incontinence attitude scale were related to nurses' attitude in relation to care of the incontinent adults. Responses on the Likert scale went from "strongly disagree" to "strongly agree". Items were scored as following, strongly disagree as 1 , disagree as 2 , agree as 3 and strongly agree as 4 . The statements were, initial involuntary loss of urine can be ignored, urinary incontinence is shameful, urinary incontinence is frustrating to take care of and managing urinary incontinence in time consuming.

\section{Ethical Considerations}

The guidelines and protocols set by the ethical committee were followed while accompanying the research. Written informed approval was taken from nurses (participants). All evidence and data collection was set aside confidential. Participants were left over unspecified throughout the study. Participants were assured that their identity will not be exposed in any publication consequential to this study.

\section{Data Collection}

For collect of data from different hospitals, permission was taken from the head nurses of the different wards and clinics to arrange suitable hours to reach the nurses participating in the study to explain the plan and procedure. At pre-set time, nurses were clarified about the study purpose of the study, and then questioner along with informed consent was distributed among nurses who participated in the study. It took about 20 to 25 minutes to solve the questioner.

\section{Data Analysis}

Data was analyzed by research supervisor and questioner was removed with missed or incomplete data, then questions and their answers were input on the IBM SPSS, version 25. The Pearson correlation test was used to correlate the knowledge, attitude and practice of urinary incontinence. Less than $\mathrm{P}>0.05$ is significant.

\section{FINDINGS AND PRESENTATION}

164 nurses contributed in the studies and 157 completed and return the survey questioner, with return rate of $95.7 \%$. Of those, $117(74.5 \%)$ were female nurses and $40(25.5 \%)$ were male nurses $146(93.0 \%)$ had diploma in general nursing, 11(7.0\%) had bachelor's degree. All $157(100 \%)$ were working in government hospital, with $31(19.4 \%)$ of work experience equals or less than 1 year, 54(34.4\%) had 2-3 years, 52(33.1\%) had 4-5years and 20(12.7\%) had 6-10 years' experience. Only $4(2.5 \%)$ had postgraduate education on urinary incontinence. Out of 157 the $79(50.3 \%)$ were evaluating patients for incontinence, 61(38.9\%) were using tool to evaluate the patients for urinary incontinence, 58(36.9\%) were providing nursing interventions for patient with urinary incontinence. Moreover only 39(24.8\%) nurses were willing to specialize in incontinence care in nursing if available. The highest obtainable score was 57 and the lowest was 0 . The scale provided data to evaluate self-reported practice of nurses with regard to UI in adults (Table 1 ). 
International Journal of Health, Medicine and Nursing Practice

ISSN 2710-1150 (Online)

Vol. 3, Issue No. 1, pp 62- 73, 2021

$\underline{\text { www.carijournals.org }}$

Table 1: Participant Characteristics and Urinary Incontinence Practices

\begin{tabular}{lc}
\hline Characteristics & $\boldsymbol{f ( \% )}$ \\
\hline Gender & \\
Female & $117(74.5)$ \\
Male & $40(25.5)$ \\
Educational attainment & \\
Diploma in General Nursing & $146(93.0)$ \\
Bachelor's degree & $11(7.0)$ \\
Workplace & \\
Government hospital & $157(100.0)$ \\
Duration of employment & \\
$\leq 1$ year & $31(19.7)$ \\
$2-3$ years & $54(34.4)$ \\
$4-5$ years & $52(33.1)$ \\
$6-10$ years & $20(12.7)$ \\
Postgraduate education on UI & \\
Yes & $4(2.5)$ \\
No & $153(97.5)$ \\
Evaluate patients for in continence & \\
Yes & $79(50.3)$ \\
No & $78(49.7)$ \\
Use tools to evaluate ui & \\
Yes & $61(38.9)$ \\
No & $96(61.1)$ \\
Provides nursing intervention for ui patients & \\
No & $58(36.9)$ \\
Willing to specialize in incontinence care nursing (if available) & $99(63.1)$ \\
Yes & \\
No & $39(24.8)$ \\
\hline
\end{tabular}

Table 2 provides the information regarding participant's knowledge towards urinary incontinence. 105(66.9\%) participants' response was true that the UTI may cause urinary incontinence. Only $38(24.2 \%)$ respondents' response was negative that urinary incontinence is normally, a part of aging. Out of 157 participants 122(77.7\%) have a knowledge that antihypertensive drugs and other medications cause urinary incontinence. Only $1(0.6 \%)$ response was false that urinary incontinence may be caused by coughing, sneezing, or running. Perianal sutures may cause urinary incontinence stated true by $62(39.50 \%)$ participants. Most of the participants true answered that involuntary urinary incontinence is called urinary incontinence. $4(2.5 \%)$ participants stated false that involuntary urinary incontinence is called stress urinary incontinence after a strong need to urinate. Mixed urinary incontinence is usually seen in immobilized patients true answered by 77(49.0\%) participants. Most of the participants $108(68.8 \%)$ answered false that urge incontinence. 2(1.3\%) answered true that urinary incontinence can only be treated by surgical intervention. 105(66.9\%) participants answered true that it is not related to persons weight. Prevention are important true stated by $153(97.5 \%)$ participants. Only 5(3.2\%) participants answered false that pelvic floor muscle exercise should be included in treatment. 41(26.1\%) participants answered true that Urinary incontinence does 
not cause an individual to become irritable, anxious and depressed. Most of the participants $116(73.9 \%)$ answered true that urinary incontinence affects the quality of life of individuals.

Table 2: Urinary Incontinence knowledge Items

\begin{tabular}{|c|c|c|c|}
\hline S/no & Variable & $\begin{array}{l}\text { True } \\
f(\%)\end{array}$ & $\begin{array}{l}\text { False } \\
f(\%)\end{array}$ \\
\hline 1 & Urinary tract infection may cause urinary incontinence. & $105(66.9)$ & $52(33.1)$ \\
\hline 2 & Urinary incontinence is a part of normal life over 65 years. & $119(75.8)$ & $38(24.2)$ \\
\hline 3 & $\begin{array}{l}\text { Antihypertensive drugs, anxiety or sleep medications can cause } \\
\text { urinary incontinence. }\end{array}$ & $122(77.7)$ & $35(22.3)$ \\
\hline 4 & Urinary incontinence may occur after prostate surgery. & $93(59.2)$ & $64(40.8)$ \\
\hline 5 & $\begin{array}{l}\text { Diseases such as diabetes mellitus, stroke, Parkinson's can } \\
\text { cause urinary incontinence. }\end{array}$ & $140(89.2)$ & $17(10.8)$ \\
\hline 6 & $\begin{array}{l}\text { Urinary incontinence may be caused by coughing, sneezing, or } \\
\text { running. }\end{array}$ & $156(99.4)$ & $1(0.6)$ \\
\hline 7 & Perianal sutures may cause urinary incontinence. & $62(39.50)$ & $95(60.5)$ \\
\hline 8 & Involuntary urinary incontinence is called urinary incontinence. & $122(77.7)$ & $35(22.3)$ \\
\hline 9 & $\begin{array}{l}\text { Involuntary urinary incontinence is called stress urinary } \\
\text { incontinence after a strong need to urinate. }\end{array}$ & $153(97.5)$ & $4(2.5)$ \\
\hline 10 & $\begin{array}{l}\text { Mixed urinary incontinence is usually seen in immobilized } \\
\text { patients. }\end{array}$ & $77(49.0)$ & $80(51.0)$ \\
\hline 11 & $\begin{array}{l}\text { A 54-year-old female patient reported "very little urine leakage } \\
\text { when exercising" and patient had urge incontinence. }\end{array}$ & $49(31.2)$ & $108(68.8)$ \\
\hline 12 & Urinary incontinence is most common in men & $30(19.1)$ & $127(80.9)$ \\
\hline 13 & $\begin{array}{l}\text { Urinary incontinence can only be treated by surgical } \\
\text { intervention. }\end{array}$ & $2(1.3)$ & $155(98.7)$ \\
\hline 14 & Urinary incontinence is not related to a person's weight & $105(66.9)$ & $52(33.1)$ \\
\hline 15 & $\begin{array}{l}\text { Regarding urinary continence and bladder health, regulation of } \\
\text { fluid intake, smoking cessation, weight loss, and constipation } \\
\text { prevention are important. }\end{array}$ & 153(97.5) & $4(2.5)$ \\
\hline 16 & $\begin{array}{l}\text { Pelvic floor muscle exercise should be included in urinary } \\
\text { incontinence treatment. }\end{array}$ & 152(96.8) & $5(3.2)$ \\
\hline 17 & $\begin{array}{l}\text { Drug therapy is not effective in the treatment of urinary } \\
\text { incontinence. }\end{array}$ & $88(56.1)$ & $69(43.9)$ \\
\hline 18 & $\begin{array}{l}\text { Prevention is a secondary method used in the treatment of } \\
\text { urinary incontinence. }\end{array}$ & $26(16.6)$ & $131(83.4)$ \\
\hline 19 & $\begin{array}{l}\text { Conservative treatment is only effective in the prevention } \\
\text { process if it is provided before urinary incontinence occurs. }\end{array}$ & $0(0.0)$ & $157(100.0)$ \\
\hline 20 & If fluid intake is restricted, incontinence decreases. & $0(0.0)$ & $157(100.0)$ \\
\hline 21 & Urinary incontinence limits the individual's social life. & $116(73.9)$ & $41(26.1)$ \\
\hline 22 & $\begin{array}{l}\text { Urinary incontinence limits the individual's daily life activities } \\
\text { and sexual life. }\end{array}$ & $0(0.0)$ & $157(100.0)$ \\
\hline 23 & $\begin{array}{l}\text { Urinary incontinence does not cause an individual to become } \\
\text { irritable, anxious and depressed. }\end{array}$ & $41(26.1)$ & $116(73.9)$ \\
\hline 24 & Urinary incontinence affects the quality of life of individuals. & $116(73.9)$ & $41(26.1)$ \\
\hline
\end{tabular}


Table 3 provides the information regarding attitude of study participants towards urinary incontinence. All of the study participants 157(100.0) disagree that initial onset of involuntary urine loss can be ignored. Only 45(28.6) study participants disagree that urinary incontinence is hard to talk. Most of the participants 148(94.3) agree that urinary incontinence is shameful. 119(75.8) out of 157 participants disagree that urinary incontinence is a person's fault. 116(73.9) participants agree that it may be prevented. Only 7(4.5) participants agree that surgical treatment of urinary incontinence is unnecessary and unsafe for the elderly. Most of the participants 135(86.0) agree that urinary incontinence is not serious. Only 5(3.2) participants agree that urinary incontinence can be effectively treated. 137(87.2) participants agree that urinary incontinence can be treated with medications. 20(12.8) participants disagree that urinary incontinence is frustrating to take care of. Only 6(3.8) participants agree that urinary problem should be reported when health problems are assessed. 100(63.6) participants disagree that managing urinary incontinence is time-consuming. 127(80.9) participants agree that family support is important in dealing with urinary incontinence. All the participants 157(100) agree that urinary incontinence is manageable. 7(4.5) out of 157 participants disagree that urinary incontinence hinders social interactions.

\section{Table 3: Urinary Incontinence Attitude Items}

\begin{tabular}{|c|c|c|c|}
\hline S/no & Variable & $\begin{array}{l}\text { Disagree } \\
f(\%)\end{array}$ & $\begin{array}{l}\text { Agree } \\
f(\%)\end{array}$ \\
\hline 1 & The initial onset of involuntary urine loss can be ignored. & $157(100.0)$ & $0(0.0)$ \\
\hline 2 & $\begin{array}{l}\text { Urinary incontinence is hard to talk about because it is an } \\
\text { embarrassing problem. }\end{array}$ & $45(28.6)$ & $112(71.4)$ \\
\hline 3 & Urinary incontinence is shameful. & $9(5.7)$ & $148(94.3)$ \\
\hline 4 & It is the person's fault if they have urinary incontinence. & $119(75.8)$ & $38(24.2)$ \\
\hline 5 & Urinary incontinence may be prevented. & $41(26.1)$ & $116(73.9)$ \\
\hline 6 & $\begin{array}{l}\text { Surgical treatment of urinary incontinence is unnecessary and } \\
\text { unsafe for the elderly. }\end{array}$ & $150(95.5)$ & $7(4.5)$ \\
\hline 7 & $\begin{array}{l}\text { Urinary incontinence is not serious enough to warrant } \\
\text { treatment. }\end{array}$ & $22(14.0)$ & $135(86.0)$ \\
\hline 8 & Urinary incontinence can be effectively treated. & $5(3.2)$ & $152(96.8)$ \\
\hline 9 & Urinary incontinence can be treated with medications. & $20(12.8)$ & $137(87.2)$ \\
\hline 10 & Urinary incontinence is frustrating to take care of. & $20(12.8)$ & $137(87.2)$ \\
\hline 11 & $\begin{array}{l}\text { Any urinary problem should be reported when health } \\
\text { problems are assessed. }\end{array}$ & $6(3.8)$ & $151(96.2)$ \\
\hline 12 & Managing urinary incontinence is time-consuming. & $100(6$ & $57(36.4)$ \\
\hline 13 & $\begin{array}{l}\text { Family support is important in dealing with urinary } \\
\text { incontinence. }\end{array}$ & $30(19.1)$ & $127(80.9)$ \\
\hline 14 & Urinary incontinence is manageable. & $0(0.0)$ & $157(100)$ \\
\hline 15 & Urinary incontinence hinders social interactions. & $7(4.5)$ & $150(95.5)$ \\
\hline
\end{tabular}

Practice regarding urinary incontinence was observed in table 4. Out of 157 88(56.1) participants were sometimes explore the amount of continent voids (a tablespoon, a cup, etc.). Only 31(19.7) participants were always inquire about alterations in bowel habit. Most of the participants 67(42.7) were never ask about use of pads, briefs, or other protective devices. 
Table 4: Urinary Incontinence Practice items

\begin{tabular}{llcccc}
\hline S/no & \multicolumn{1}{c}{ Variable } & $\begin{array}{c}\text { Always } \\
\boldsymbol{f ( \% )}\end{array}$ & $\begin{array}{c}\text { Usually } \\
\boldsymbol{f ( \% )}\end{array}$ & $\begin{array}{c}\text { Sometimes } \\
\boldsymbol{f ( \% )}\end{array}$ & $\begin{array}{c}\text { Never } \\
\boldsymbol{f ( \% )}\end{array}$ \\
\hline 1 & $\begin{array}{l}\text { Explore the amount of continent } \\
\text { voids (a tablespoon, a cup, etc.). }\end{array}$ & $7(4.5)$ & $19(12.1)$ & $88(56.1)$ & $43(27.4)$ \\
2 & $\begin{array}{l}\text { Inquire as to alterations in bowel } \\
\text { habit. }\end{array}$ & $31(19.7)$ & $11(7.0)$ & $45(28.7)$ & $70(44.6)$ \\
3 & $\begin{array}{l}\text { Ask about use of pads, briefs, or } \\
\text { other protective devices. }\end{array}$ & $27(17.2)$ & $4(2.5)$ & $59(37.6)$ & $67(42.7)$ \\
\hline
\end{tabular}

Obstacles to urinary incontinence care were showed in table 5. Most 103(65.6) of the participants were agree that there is lack of system for follow-up patients. 82(52.2) participants agree that at home patients not completing urinary incontinence treatment task. Out of 157 participants 104(66.2) disagree that urinary incontinence patients not being referred to nurses in outpatient clinics. 73(46.5) participants disagree that there is lack of patient standard record form. Only 25(15.9) participants disagree that there is lack of urinary incontinence trainings for nurses. 101(64.3) participants agree that treatment being rendered by physicians. Only 56(35.7) participants agree that urinary incontinence treatment in long-term nursing care. Most of the participants were agree that nurses not being assigned to provide urinary incontinence care.

Table 5: Obstacles to Urinary Incontinence Care

\begin{tabular}{llcc}
\hline S/no & \multicolumn{1}{c}{ Variable } & $\begin{array}{c}\text { Agree } \\
\boldsymbol{f ( \% )}\end{array}$ & $\begin{array}{c}\text { Disagree } \\
\boldsymbol{f}(\boldsymbol{\%})\end{array}$ \\
\hline 1 & Lack of systems for patient follow-up & $103(65.6)$ & $54(34.4)$ \\
2 & $\begin{array}{l}\text { Patient not completing urinary incontinence treatment tasks } \\
\text { at home }\end{array}$ & $82(52.2)$ & $75(47.8)$ \\
3 & Patient lack of interest & $41(26.1)$ & $116(73.9)$ \\
4 & Lack of patient education materials & $80(51.0)$ & $77(49.0)$ \\
5 & Lack of the physical space in the hospital to evaluate and train & $77(49.0)$ & $80(51.0)$ \\
& patients & & \\
6 & Urinary incontinence patients not being referred to nurses in & $53(33.8)$ & $104(66.2)$ \\
& outpatient Clinics & & \\
7 & Lack of patient standard record forms & $84(53.5)$ & $73(46.5)$ \\
8 & Lack of urinary incontinence training for nurses & $132(84.1)$ & $25(15.9)$ \\
9 & Treatment being rendered by physicians & $101(64.3)$ & $56(35.7)$ \\
10 & Urinary incontinence treatment in long-term nursing care & $56(35.7)$ & $101(64.3)$ \\
11 & Nurses not being assigned to provide urinary incontinence & $108(68.8)$ & $49(31.2)$ \\
& care & & \\
\hline
\end{tabular}

There is a significant correlation found between knowledge and attitude items of urinary incontinence (table 5). 
Table 6: Correlations Between Knowledge and Attitude Items

\begin{tabular}{llcc}
\hline & & Knowledge score & Attitude score \\
\hline Knowledge & Pearson Correlation & 1 & $-.159^{*}$ \\
score & Sig. (2-tailed) & & .046 \\
& $\mathrm{~N}$ & 157 & 157 \\
Attitude score & Pearson Correlation & $-.159^{*}$ & 1 \\
& Sig. (2-tailed) & .046 & \\
& $\mathrm{~N}$ & 157 & 157 \\
\hline
\end{tabular}

Table 7 provides the information that there is a significant correlation between knowledge and practice items of urinary incontinency.

Table 7: Correlations Between Knowledge and Practice Items

\begin{tabular}{llcc}
\hline & & Knowledge score & Practice Score \\
\hline Knowledge & Pearson Correlation & 1 & $.165^{*}$ \\
score & Sig. (2-tailed) & & .039 \\
& $\mathrm{~N}$ & 157 & 157 \\
Practice Score & Pearson Correlation & $.165^{*}$ & 1 \\
& Sig. (2-tailed) & .039 & \\
& $\mathrm{~N}$ & 157 & 157 \\
\hline
\end{tabular}

\section{DISCUSSIONS AND CONCLUSION}

\section{Discussions}

The research questions addressed in this article were developed instruments and had reliable and valid measures of nurses' knowledge, attitude, practice and obstacles in previous studies. The urinary incontinence knowledge table was established by the researchers' existing literature.

A cross-sectional descriptive study was conducted in Turkey comprising 304 health care professionals (HCPs) to addressed knowledge, attitudes, and behaviors regarding execution and teaching of pelvic floor muscle exercise, 18 nurses were found with lowermost level of knowledge of UI among HCP which they gained in nursing schools. Another 6 months randomized controlled study in UK has prevailed that urinary incontinence treatment-based training for licensed nurses $25(\mathrm{~N}=295)$ after nursing school education have found significantly reduce the episodes of urinary incontinence. The results of this study were almost the same as those gathered in other countries. It was concluded from this study that the desired level of knowledge is not enough for nurse to make them able to provide satisfactory care to the patients with UI. It is necessary to have adequate knowledge when nurses are playing role as trainer or consultant in different practice fields (Caliskan, Gulnar, Aydogan, Bayram, \& Yagci, 2019).

An optimistic attitude is necessary to put knowledge into practice as knowledge without help of attitude is not adequate for positive behavior. Practice short fall is a gap between knowledge and practice which suppress positive attitudes towards UI (Kelly \& Byrne, 2006). However, many cross-sectional studies have shown that many nurses have very low knowledge of prevention, treatment and management of UI (Keilman \& Dunn, 2010). 


\section{Conclusion}

It is concluded that nurses have good knowledge, positive attitude but wrong practices that require special training or workshops to managing and treating incontinence more efficiently. This helps to bring significant improvement in urinary incontinence care and helps to lower the heath care cost. Such clinical guidelines need to be made within the organizations to manage a significant proportion of patients with urinary incontinence. In Pakistan there is lack knowledge and communication skills lowers providing continence care. There is evidence in many countries like US, India and UK that clients appreciate the good communication skills provided by nurses, therefore they endorse that a continence nurse specialist should deliver basic continence care. A combined public health movement is required to build the profile of urinary continence care in Lahore, Pakistan. The part of community centered support is important but also difficult to apply. Urinary incontinence campaign can help increase awareness in primary health care workers who are in a perfect place to take on the role of case detection. Moreover, specific training or workshops in incontinence may improve the numbers successfully seeking help for urinary incontinence.

\section{REFERENCES}

Abrams, P., Andersson, K. E., Apostolidis, A., Birder, L., Bliss, D., Brubaker, L., . . Wein, A. (2018). 6th International Consultation on Incontinence. Recommendations of the International Scientific Committee: Evaluation And Treatment Of Urinary Incontinence, Pelvic Organ Prolapse And Faecal Incontinence. Neurourol Urodyn, 37(7), 2271-2272. doi:10.1002/nau.23551

Caliskan, N., Gulnar, E., Aydogan, S., Bayram, S. B., \& Yagci, N. J. W. M. P. (2019). Obstacles to providing urinary incontinence care among nurses in Turkey: a descriptive study. 65, 36-47.

Franken, M. G., Corro Ramos, I., Los, J., \& Al, M. J. (2018). The increasing importance of a continence nurse specialist to improve outcomes and save costs of urinary incontinence care: an analysis of future policy scenarios. BMC Fam Pract, 19(1), 31. doi:10.1186/s12875-018-0714-9

Henderson, J. S., Kashka, M. S., \& Larson, A. J. U. N. (2000). Effect of knowledge, attitude, and belief on nurses' practice regarding urinary incontinence in adults. 20(5), 291-292.

Hu, J. S., \& Pierre, E. F. (2019). Urinary Incontinence in Women: Evaluation and Management. Am Fam Physician, 100(6), 339-348.

Jang, Y., Kwon, B. E., Kim, H. S., Lee, Y. J., Lee, S., Kim, S. J., . . Kim, K. H. (2015). Knowledge and Practice Behaviors Regarding Urinary Incontinence Among Korean Healthcare Providers in Long-term Care Hospitals. Int Neurourol J, 19(4), 259-264. doi:10.5213/inj.2015.19.4.259

Jokhio, A., Rizvi, R., Rizvi, J., MacArthur, C. J. B. A. I. J. o. O., \& Gynaecology. (2013). Urinary incontinence in women in rural Pakistan: prevalence, severity, associated factors and impact on life. 120(2), 180-186.

Keilman, L. J., \& Dunn, K. S. (2010). Knowledge, attitudes, and perceptions of advanced practice nurses regarding urinary incontinence in older adult women. Res Theory Nurs Pract, 24(4), 260-279. doi:10.1891/1541-6577.24.4.260

Kelly, A. M., \& Byrne, G. (2006). Role of the continence nurse in health promotion. Br J Nurs, 15(4), 198-204. doi:10.12968/bjon.2006.15.4.20544 
Khandelwal, C., \& Kistler, C. (2013). Diagnosis of urinary incontinence. Am Fam Physician, 87(8), 543-550.

Kok, G., Seven, M., Guvenc, G., \& Akyuz, A. (2016). Urinary Incontinence in Pregnant Women: Prevalence, Associated Factors, and Its Effects on Health-Related Quality of Life. $J$ Wound Ostomy Continence Nurs, 43(5), 511-516. doi:10.1097/won.0000000000000262

Lukacz, E. S., Santiago-Lastra, Y., Albo, M. E., \& Brubaker, L. J. J. (2017). Urinary incontinence in women: a review. 318(16), 1592-1604.

Saxer, S., de Bie, R. A., Dassen, T., \& Halfens, R. J. (2009). Knowledge, beliefs, attitudes, and self-reported practice concerning urinary incontinence in nursing home care. $J$ Wound Ostomy Continence Nurs, 36(5), 539-544. doi:10.1097/WON.0b013e3181b35ff1

Stickley, A., Santini, Z. I., \& Koyanagi, A. J. B. u. (2017). Urinary incontinence, mental health and loneliness among community-dwelling older adults in Ireland. 17(1), 1-9.

Syan, R., \& Brucker, B. M. (2016). Guideline of guidelines: urinary incontinence. BJU Int, 117(1), 20-33. doi:10.1111/bju.13187

Thüroff, J. W., Abrams, P., Andersson, K. E., Artibani, W., Chapple, C. R., Drake, M. J., . . . Tubaro, A. (2011). EAU guidelines on urinary incontinence. Eur Urol, 59(3), 387-400. doi:10.1016/j.eururo.2010.11.021

Ting, H. Y., \& Cesar, J. A. (2020). Urinary incontinence among pregnant women in Southern Brazil: A population-based cross-sectional survey. PLoS One, 15(6), e0234338. doi:10.1371/journal.pone.0234338

Vinsnes, A. G., Harkless, G. E., Haltbakk, J., Bohm, J., \& Hunskaar, S. J. J. o. c. n. (2001). Healthcare personnel's attitudes towards patients with urinary incontinence Information Point: Regression analysis. 10(4), 455-462.

Wood, L. N., \& Anger, J. T. (2014). Urinary incontinence in women. Bmj, 349, g4531. doi:10.1136/bmj.g4531

Yaqub, U., Habib, M., \& Shaheen, T. J. P. A. F. M. J. (2019). Frequency Of Urinary Incontinence (Ui) And Its Associated Risk Factors In Pregnant Population. 69(1), 117 122.

Yuan, H., Williams, B. A. J. H., \& community, s. c. i. t. (2010). Knowledge of urinary incontinence among Chinese community nurses and community-dwelling older people. 18(1), 82-90.

Yuan, H. B., Williams, B. A., Liu, M. J. J. o. W. O., \& Nursing, C. (2011). Attitudes toward urinary incontinence among community nurses and community-dwelling older people. $38(2), 184-189$. 